The University of Maine

\title{
DigitalCommons@UMaine
}

Scientific Articles

Publications

Winter 11-23-2010

\section{Ingestion of Lepeophtheirus salmonis by the blue mussel Mytilus edulis}

Deborah A. Bouchard

Ian Bricknell

Sally Malloy

Michael Pietrak

Follow this and additional works at: https://digitalcommons.library.umaine.edu/ari_articles

\section{Repository Citation}

Bouchard, Deborah A.; Bricknell, Ian; Malloy, Sally; and Pietrak, Michael, "Ingestion of Lepeophtheirus salmonis by the blue mussel Mytilus edulis" (2010). Scientific Articles. 1.

https://digitalcommons.library.umaine.edu/ari_articles/1

This Article is brought to you for free and open access by DigitalCommons@UMaine. It has been accepted for inclusion in Scientific Articles by an authorized administrator of DigitalCommons@UMaine. For more information, please contact um.library.technical.services@maine.edu. 


\title{
Ingestion of Lepeophtheirus salmonis by the blue mussel Mytilus edulis
}

\author{
Sally D. Molloy ${ }^{1}$, Michael R. Pietrak ${ }^{1}$, Deborah A. Bouchard ${ }^{2}$, Ian Bricknell ${ }^{*}$ \\ Aquaculture Research Institute, 5735 Hitchner Hall, University of Maine, Orono, ME 04469-5735, USA
}

\section{A R T I C L E I N F O}

Article history:

Received 1 November 2010

Accepted 23 November 2010

Available online 30 November 2010

\section{Keywords:}

Integrated-multi-trophic aquaculture

Sea lice

Mussels

Atlantic salmon

\begin{abstract}
A B S T R A C T
Integrated multi-trophic aquaculture (IMTA) is an exciting alternative approach to mono-culture aquaculture that reduces environmental impacts of commercial aquaculture systems by combining the cultivation of fed aquaculture species (finfish) with extractive aquaculture species (e.g., shellfish and seaweed). This increases the sustainability and profitability of finfish culture as the organic particulate wastes can be removed by the shellfish extractive component and dissolved inorganic nutrients are extracted by the seaweed component. Shellfish play a critical role in an IMTA system by extracting particulate bound organic nutrients; however they may also influence pathogen dynamics by serving as a reservoir or as a barrier for finfish pathogens, depending on pathogen physiologies. The sea louse, Lepeophtheirus salmonis, has recently made a spectacular comeback as a major parasitic pest of farmed Atlantic salmon (Salmo salar L.) in the Northeast of the United States. The re-emergence of this parasite is due to development of louse resistance to SLICE ${ }^{\mathrm{TM}}$, the drug of choice for treating L. salmonis infestations over the last decade. Incorporation of mussel crops on salmon farms may be an alternative method to reduce the infectious pressure of sea lice on farms if mussels can consume copepodids, the planktonic and infectious stage of sea lice. Our study demonstrated that mussels can remove copepodids from the water column. Individual mussels were exposed to copepodids (200 copepodids $\mathrm{1}^{-1}$ ) for 30- and 60-min durations. Copepodids were observed in the buccal cavity and in stomach contents. Molecular analyses confirmed the presence of copepodids in mussel stomach contents.
\end{abstract}

(c) 2010 Elsevier B.V. All rights reserved.

\section{Introduction}

The sea louse, Lepeophtheirus salmonis, Kröyer 1837, has recently made a comeback as a major parasitic pest of farmed salmon in the Northeastern United States. It is now considered a major economic threat to commercial Atlantic salmon (Salmo salar L.) culture in the North Atlantic. One of the main reasons for the re-emergence of this parasite is the development of louse resistance to SLICE ${ }^{\mathrm{TM}}$, the drug of choice for treating $L$. salmonis infestations over the last decade.

The life cycle of the sea louse consists of two planktonic nauplii stages (Johannessen 1978, Johnson \& Albright 1991a, b), the infective copepodid stage and seven stages completed on the host (Johnson \& Albright 1991a, b, Pike \& Wadsworth 1999). To date all control measures developed to fight sea lice have targeted one or more of the stages on the host salmonid. Most treatments involve chemotheraputants of various types; however farmers in northern Europe also use several native species of wrasse as a biological control (Roth 2000, Treasurer 2002). In North America management control measures

\footnotetext{
* Corresponding author. Tel.: +1 207581 4380; fax: +1 2075814388. E-mail addresses: sally.dixon@umit.maine.edu (S.D. Molloy), mike@maineaquaculture.com (M.R. Pietrak), deborah.bouchard@maine.edu (D.A. Bouchard), ian.bricknell@umit.maine.edu (I. Bricknell).

${ }^{1}$ Tel.: +1 207581 4337; fax: + 12075814388 .

2 Tel.: +1 207581 2767; fax: +1 2075814388 .
}

have been limited to one or two available chemotheraputants, and reducing fish densities. Our research group proposes an alternative for lice management with the hypothesis that incorporation of mussel crops on salmon farms may reduce the infectious pressure of sea lice on farms if mussels can consume copepodids.

On the eastern coast of North America salmon farmers are exploring an integrated multi-trophic aquaculture (IMTA) approach that incorporates culture systems for suspended blue mussels (Mytilus edulis) and various kelps at sites with net pen culture of Atlantic salmon. IMTA is an exciting alternative approach to monoculture aquaculture that reduces environmental impacts of commercial aquaculture systems while increasing sustainability, profitability and public acceptance (Ridler et al. 2007). By combining the cultivation of fed aquaculture species (finfish) with extractive aquaculture species (e.g., shellfish and seaweed) organic particulate wastes such as uneaten fish food are removed by the shellfish extractive component and dissolved inorganic nutrients are extracted by the seaweed component (Troell et al. 2003). Our research group has been focusing on disease dynamics on an IMTA farm using a simplified model consisting of finfish and mussels co-cultured on the same site.

This study was conducted to determine if mussels ingest sea lice copepodids therefore possibly having the potential to reduce infectious pressure of the sea louse on integrated salmon and mussel farms. Mussels were exposed to known numbers of copepodids for 30 - and 60-min durations after which ingestion was confirmed by 
observations of copepodids in mussel stomach content and molecular analysis of mussel stomach contents.

\section{Materials and methods}

\subsection{Sea lice and mussel maintenance}

Mussels were obtained from a local commercial mussel farmer and placed in a re-circulating system containing artificial sea water (ASW) (Crystal Seas Marine Mix) (Marine Enterprises, Baltimore, MD) maintained at $10^{\circ} \mathrm{C}$. They were fed a commercial algae paste containing a mix of species (Innovative Aquaculture, Starter Formula).

Sea lice were hatched from egg strings collected from an infected commercial Atlantic salmon farm in Maine. The egg strings were hatched and the nauplii were reared to the copepodid stage in a system similar to that described by Pietrak \& Opitz (2004). The system was modified to have three floating egg containers ( 8 inches by 4 inch diameter). The egg containers were suspended in a $165 \mathrm{~L}$ system with natural seawater at $12{ }^{\circ} \mathrm{C}$.

\subsection{Mussel exposures to Lepeophtheirus salmonis}

Sea lice larvae were stained for $1 \mathrm{~h}$ in $1 \mathrm{~L}$ of $12{ }^{\circ} \mathrm{C}$ aerated ASW containing $0.015 \mathrm{~g}$ of neutral red (Anstensrud 1989, 1990). Stained sea lice were examined under a dissecting scope for viability and life stage before being counted. In sea lice only treatments $(n=7)$, beakers contained $0.5 \mathrm{~L}$ of seawater, $10^{5}$ cells $/ \mathrm{ml}$ algae, and 100 copepodids (200 copepodids $1^{-1}$ ). For mussel and sea lice treatments $(n=10)$, individual mussels of similar size were placed in 10 replicate 1 -L beakers containing $0.5 \mathrm{~L}$ of aerated $12{ }^{\circ} \mathrm{C}$ ASW, $10^{5}$ cells/ml algae, and 100 copepodids. Mussels were exposed to sea lice copepodids for $30 \mathrm{~min}(n=5)$ or $60 \mathrm{~min}(n=5)$ after each mussel began filtering seawater. Immediately after removing mussels from beakers, an incision was made in the stomach and stomach contents were removed with a sterile Pasteur pipette. Stomach contents were examined for the presence of stained copepodids then processed for DNA isolation. The number of copepodids in the interior of the mussel, in the feces and pseudofeces was determined visually. The freeswimming copepodids remaining in each beaker were removed from the seawater using a $100-\mu \mathrm{m}$ cell strainer and transferred to a petri dish containing $100 \%$ ethanol before counting.

The stomach contents were removed from 6 additional mussels after $30 \mathrm{~min}$ in $0.5 \mathrm{~L}$ of seawater containing $10^{5}$ cells $/ \mathrm{ml}$ algae but without copepodids. These samples were spiked with $0,1,510,15$ or 20 stained copepodids and processed for DNA isolation. A one-way ANOVA analysis with an alpha level of 0.05 was performed to determine that there was no significant difference in shell length $(\mathrm{cm})$ between mussels used in each experiment $(F=0, p=1.0)$.

\subsection{DNA isolation and $q P C R$ detection of $L$. salmonis}

Mussel stomach content samples were incubated overnight at $55^{\circ} \mathrm{C}$ in ATL buffer (Qiagen, Valencia, CA) containing proteinase $\mathrm{K}$ $(2 \mathrm{mg} / \mathrm{ml})$ (Qiagen). DNA was extracted from mussel stomach contents using the DNeasy Blood and Tissue kit (Qiagen) according to the manufacturer's recommendations. DNA concentrations ranged from $31.4 \mathrm{ng} / \mu \mathrm{l}$ to $467.4 \mathrm{ng} / \mu \mathrm{l}$ with all but two samples being greater than $100 \mathrm{ng} / \mu \mathrm{l}$. Lysates of 1,5 and 10 copepodids were prepared for quantitative PCR (qPCR) positive controls according to McBeath et al. (2006). qPCR detection of the mitochondrial cytochrome oxygenase I (mtCOI) gene specific to $L$. salmonis was carried out according to McBeath et al. (2006). Briefly, $1 \mu \mathrm{l}$ of DNA samples diluted 10 -fold were added to triplicate $20-\mu l$ real-time PCR reactions containing $1 \times$ Perfecta qPCR Supermix (Quanta Biosciences, Gaithersburg, MD), 900 $\mathrm{nM}$ of each primer and $200 \mathrm{nM}$ of Taqman ${ }^{\circledR}$ probe. qPCR assays were performed in the MX4000 detection system (Stratagene, Santa Clara,
CA) using the following thermal profile: $45^{\circ} \mathrm{C}$ for $2 \mathrm{~min}, 95^{\circ} \mathrm{C}$ for $10 \mathrm{~min}$ followed by 45 cycles of $95^{\circ} \mathrm{C}$ for $15 \mathrm{~s}$ and $60{ }^{\circ} \mathrm{C}$ for $1 \mathrm{~min}$.

\section{Results}

The mean cycle threshold (CT) values for samples spiked with 1, 5, 10,15 and 20 copepodids are presented in Table 1 . The CT values decrease in a linear fashion with increasing numbers of copepodids added to the sample until 15 or more copepodids are added. The CT values associated with 15 (24.72) and 20 (24.36) copepodids were higher than the predicted CT values (23.3 and 21.5 respectively).

The number of free-swimming copepodids remaining after each filter feeding experiment is presented in Table 2. After $30 \mathrm{~min}, 87-98$ free-swimming copepodids remained in the beakers of mussel numbers 2-5. There were 59 remaining copepodids in seawater samples from mussel numbers 1 and 6 ; however these counts may be underestimated since small amounts of water from both samples were spilled during processing. After $60 \mathrm{~min}, 38-100$ free-swimming copepodids remained in seawater samples from mussel numbers 710. The average numbers of free-swimming copepodids in the control beakers for the 30- and 60-min filter feeding experiments were 99 $(n=5)$ and $98.5(n=2)$.

Mussels ingest copepodids in the presence of algae within 3060 min of exposure to 200 copepodids $1^{-1}$. Copepodids were observed in the interior of all 5 mussels exposed to copepodids for $30 \mathrm{~min}$ (Table 2). In mussel numbers 1 and 5, 1-2 copepodids respectively, were observed in the stomach contents. Copepodids were also observed on the gills, in the buccal cavity, on the interior of the mantle or on the foot. Copepodids were observed in the pseudofeces of two mussels exposed for $30 \mathrm{~min}$. qPCR assays targeting the $\mathrm{mtCOI}$ gene of $L$. salmonis, confirmed the presence of copepodids in the stomach contents (Table 1). CT values of 28.05 and 25.58 resulted from qPCR assays performed on DNA isolated from stomach contents from mussel numbers 1 and 5 respectively. Similar CT values resulted from qPCR assays performed on DNA isolated from mussel stomach contents spiked with 1 and 10 copepodids (28.27 and 25.05).

After 60 min exposure to 200 copepodids $1^{-1}, 4$ out of 5 mussels ingested copepodids (Table 2). Copepodids were observed in the stomach contents of mussel numbers 7, 8 and 9. A large aggregate of stained copepodids was observed at the end of the crystal stylus of mussel number 9. Because it was difficult to determine the number of copepodids in the aggregate, an estimation of 10-15 copepodids was made. The CT value (24.93) that resulted from qPCR analysis of this stomach content sample correlated with the CT values that resulted from qPCR analysis of mussel stomach contents spiked with 10-15

\section{Table 1}

Cycle threshhold (CT) values resulting from qPCR analysis of DNA isolated from mussel stomach contents.

\begin{tabular}{llll}
\hline $\begin{array}{l}\text { Mussel } \\
\text { sample }\end{array}$ & $\begin{array}{l}\text { Duration of } \\
\text { experiment (min) }\end{array}$ & $\begin{array}{l}\text { Observed } \\
\text { copepodids in gut }\end{array}$ & $\begin{array}{l}\text { Average CT } \\
\text { value }\end{array}$ \\
\hline 1 & 30 & 1 & 28.05 \\
2 & 30 & 0 & No CT \\
3 & 30 & 0 & No CT \\
4 & 30 & 0 & No CT \\
5 & 30 & 2 & 25.58 \\
6 & 60 & 0 & 28.46 \\
7 & 60 & 9 & 31.34 \\
8 & 60 & 2 & 27.14 \\
9 & 60 & $10-15$ & 24.93 \\
10 & 60 & 0 & 43.39 \\
Control mussel & & 0 & No CT \\
Control mussel & & 1 & 28.27 \\
Control mussel $^{\mathrm{a}}$ & & 5 & 27.12 \\
Control mussel $^{\mathrm{a}}$ & & 10 & 25.05 \\
Control mussel $^{\mathrm{a}}$ & & 15 & 24.72 \\
Control mussel $^{\mathrm{a}}$ & & 20 & 24.36 \\
\hline
\end{tabular}

a Copepodids added to stomach content samples. 
Table 2

Number of copepodids observed free-swimming in the water and within mussels after 30- and 60-min exposures.

\begin{tabular}{|c|c|c|c|c|c|}
\hline \multirow[b]{2}{*}{$\begin{array}{l}\text { Mussel } \\
\text { sample }\end{array}$} & \multirow[b]{2}{*}{$\begin{array}{l}\text { Duration of } \\
\text { experiment }(\mathrm{min})\end{array}$} & \multicolumn{4}{|c|}{ Number of observed copepodids } \\
\hline & & $\begin{array}{l}\text { Free- } \\
\text { swimming }\end{array}$ & Pseudofeces & $\begin{array}{l}\text { Total Observed } \\
\text { Ingested }^{\mathrm{a}}\end{array}$ & Gut \\
\hline 1 & 30 & $59^{\mathrm{b}}$ & 3 & 5 & 1 \\
\hline 2 & 30 & 87 & 0 & 2 & 0 \\
\hline 3 & 30 & 98 & 0 & 3 & 0 \\
\hline 4 & 30 & 96 & 2 & 4 & 0 \\
\hline 5 & 30 & 92 & 0 & 2 & 2 \\
\hline $\begin{array}{l}\text { Control } \\
\qquad(n=5)\end{array}$ & 30 & $99^{c}$ & - & - & - \\
\hline 6 & 60 & $59^{\mathrm{b}}$ & 0 & 2 & 0 \\
\hline 7 & 60 & 38 & 0 & 11 & 9 \\
\hline 8 & 60 & 103 & 0 & 2 & 2 \\
\hline 9 & 60 & 40 & 0 & $20-25$ & $10-15$ \\
\hline 10 & 60 & 100 & 0 & 0 & 0 \\
\hline $\begin{array}{l}\text { Control } \\
\qquad(n=2)\end{array}$ & 60 & $98.5^{c}$ & - & - & - \\
\hline
\end{tabular}

a Total number of observed copepodids in gut, gill, mantle, buccal cavity, or on foot.

b Sample loss due to spill.

c Average number of copepodids.

copepodids (25.05 and 24.72). In the stomach contents of mussel number 7, 9 copepodids were observed; however the resulting CT value from qPCR analysis (31.24) was higher than the CT values associated with only one copepodid, indicating a problem with this sample. The concentration of DNA isolated from the stomach contents of mussel number $9(31.4 \mathrm{ng} / \mu \mathrm{l})$ was much lower compared to that of other samples. Quantitative PCR assays performed on stomach content DNA from mussels receiving the no-copepodid treatment were negative.

\section{Discussion}

Incorporation of mussel crops on salmon farms may be an alternative method to reduce the infectious pressure of sea lice on farms if mussels can consume copepodids. Our study demonstrated that mussels do ingest the copepodid stage of sea lice. Copepodids were observed on mussel structures such as the gills, foot, and mantle and in the mussel stomach contents after 30- and 60-min filter feeding experiments (Table 2). Further, the presence of copepodids in the mussel stomach contents was confirmed by qPCR targeting a mtCOI sequence that is specific to L. salmonis (Table 1 ).

The CT values resulting from spiked samples decreased in a linear fashion with increasing numbers of copepodids added to the sample. The sample spiked with 10 copepodids resulted in a CT value (25.05) that is nearly 3.3 cycles less than that of the sample spiked with 1 copepodid (28.27). This is the expected decrease in CT value for qPCR carried out with $100 \%$ efficiency on 10 -fold dilutions of the DNA template. However, samples receiving greater than 10 copepodids were associated with higher CT values than expected. Although qPCR was carried out on 10-fold dilutions of the original DNA samples, these samples may have still contained PCR inhibitors. An endogenous positive control was not used in these reactions as in McBeath et al. and therefore there was no way of detecting PCR inhibition (McBeath et al. 2006).

qPCR consistently detected copepodids in every mussel stomach content sample, in which copepodids were observed. In the case of mussel number 6, qPCR resulted in a CT value that indicated at least 1 copepodid was present in the stomach content sample, although no copepodids were observed in this sample. CT values associated with DNA samples from mussel numbers 1,8 and 9 (28.05, 27.14 and 29.43) correlated well with CT values associated with stomach content samples spiked with 1, 5 and 10 copepodids (28.27, 28.12 and 25.05). CT values associated with stomach content samples from mussel numbers 5 and 7 did not correlate well with CT values from spiked stomach content samples. Two copepodids were observed in the stomach content sample of mussel number 5, however the CT value, 25.58 was lower than the CT value associated with 5 copepodids added to control stomach content samples (27.12). It is possible that more than 2 copepodids were present in the sample number 5 but were unobserved. The CT value that resulted from qPCR performed on DNA isolated from mussel number 9 (31.34) was too high for the 9 observed copepodids in the sample. The concentration of DNA of this sample was much lower than that of all the other DNA samples and it is possible that an inefficient DNA extraction resulted in the increased PCR cycles necessary for detection. The qPCR assay provides a more sensitive method for detecting copepodids in mussel stomach contents. Copepodids were detected by qPCR in all samples in which copepodids were observed and in samples in which no copepodids were observed. Copepodids may be more difficult to recognize in stomach contents after digestion begins. qPCR performed on the spiked stomach content samples provides at best an estimate of 1 , greater than 1 , or greater than 10 copepodids present in a sample.

Only 4 out of the 5 mussels in the 60-min exposure ingested copepodids and the range of observed, ingested copepodids ranged from 2 to more than 20 copepodids. Time for each filter feeding experiment was begun when the mussel was observed to open and begin filtering. It is possible that some mussels may have opened for respiration and had not started feeding until partially through the allotted time. This might explain some of the variation in the number of copepodids ingested among the mussels, particularly in the 60-min experiment. Mussel number 10 was observed filtering water; however did not ingest any of the 100 copepodids. It is probable that mussel number 10 was not feeding during the experiment, despite the addition of algae to the beaker.

The number of free-swimming copepodids remaining in the beaker after removal of the mussel, in some cases, exceeded the expected total number of copepodids of 100 (mussel numbers 3, 4, and 8). It is likely that an error was made in counting the live copepodids and more than 100 copepodids were placed in the beaker prior to adding the mussel. The remaining number of free-swimming copepodids in beakers of mussel numbers 1,2, 6, 7, and 9 were lower than expected given the number of copepodids observed inside the mussel (Table 2). Some of the unaccounted copepodids for mussel numbers 1 and 6 may be due to spillage of seawater samples during the counting process. However large losses of free-swimming copepodids were observed in the seawater samples from mussel numbers 2, 7 and 9 (Table 2) where no sample loss occurred. The number of free-swimming copepodids in control beakers incubated without mussels for 30 - and 60-min durations had losses of copepodids no greater than 2 copepodids indicating that the counting methods pre- and post experiment are not likely responsible for such high losses. While it is possible that small errors during counting occurred, the high number of unaccounted copepodids, as many as 51, is likely due to ingestion by the mussels. These copepodids may have been further along in the digestive system, beyond the stomach, and therefore were not observed.

It is not surprising that mussels feed on sea lice copepodids. While mussels are known to ingest phytoplankton they also take up large numbers of micro- and mesozooplankton, including crustaceans (Davenport et al. 2000). Davenport et al. demonstrated 90\% uptake of Artemia nauplii $(300 \mu \mathrm{m})$ and $46 \%$ uptake of the adult copepod Tigriopus brevicornis ( $1 \mathrm{~mm}$ ) by mussels. The size of the copepodid (780-830 $\mu \mathrm{m}$ ) falls within the size range of the crustaceans used in the mussel filter feeding experiments carried out by Davenport et al. (2000) (Schram 2004).

Our study clearly demonstrated that mussels are capable of removing sea lice copepodids from the water column. While it is encouraging that mussels feed on the copepodid stage of the sea louse, it is not yet known whether mussels have the potential to remove and 
inactivate free-swimming sea lice at a rate and quantity sufficient to decrease sea lice density at a farm site. Laboratory trials and field trials that include mussels, salmon and sea lice will be necessary to determine if the co-culture of mussels may be used as a new disease management strategy for sea lice.

\section{References}

Anstensrud, M., 1989. A vital stain for studies of behaviour and ecology of the parasitic copepod Lernaeocera branchialis (Pennellidae). Mar. Ecol. Prog. Ser. 53, 47-50.

Anstensrud, M., 1990. Mating strategies of two parasitic copepods [(Lernaeocera branchialis (L.) (Pennellidae) and Lepeophtheirus pectoralis (Mueller) (Calagidae)] on flounder: polygamy, sex-specific age at maturity and sex ratio. J. Exp. Mar. Biol. Ecol. 136, 141-158.

Davenport, J., Smith, R., Packer, M., 2000. Mussels Mytilus edulis: significant consumers and destroyers of mesoplankton. Mar. Ecol. Prog. Ser. 198, 131-137.

Johannessen, A., 1978. Early stages of Lepeophtheirus salmonis (Copepoda, Caligidae). Sarsia 63, 169-176.

Johnson, S.C., Albright, L.J., 1991a. Development, growth, and survival of Lepeophteirus salmonis (Copepoda: Caligidae). J. Mar. Biol. Ass. UK 2, 425-436.
Johnson, S.C., Albright, L.J., 1991b. The developmental stages of Lepeophtheirus salmonis (Kroyer, 1837) (Copepoda: Caligidae). Can. J. Zool. 69, 929-950.

McBeath, A., Penston, M., Snow, M., Cook, P., Bricknell, I., Cunningham, C., 2006 Development and application of real-time PCR for specific detection of Lepeophtheirus salmonis and Caligus elongatus larvae in Scottish plankton samples. Dis. Aquat. Org. 73, 141-150.

Pietrak, M., Opitz, H.M., 2004. An evaluation of three potential methods for preventing the spread of larval Lepeotheirus salmonis (Kroyer, 1837). Aquac. Res. 35, 759-763.

Pike, A.W., Wadsworth, S.L., 1999. Sealice on slamonids: their biology and control. Academic Press, San Diego.

Ridler, N., Wowchuk, M., Robinson, B., Barrington, K., Chopin, T., 2007. Integrated multitrophic aquaculture (IMTA): a potential strategic choice for farmers. Aquac. Econ. Manag. 11, 99-110.

Roth, M., 2000. The availability and use of chemotherapeutic sea lice control products Contrib. Zool. 69, 109-118.

Schram, T.A., 2004. Practical identification of pelagic sea lice larvae. J. Mar. Biol. Assoc UK 84, 103-110.

Treasurer, J.W., 2002. A review of potential pathogens of sea lice and the application of cleaner fish in biological control. Pest. Manag. Sci. 58, 546-568.

Troell, M., Halling, C., Noeri, A., Chopin, T., Buschmann, A.H., Kautsky, N., Yarish, C., 2003. Integrated mariculture: asking the right questions. Aquaculture 226, 69-90. 